\title{
Synthesis and anticancer activity of novel quinazolinone-based rhodanines
}

\author{
Sherihan El-Sayed ${ }^{1 *} \mathbb{0}$, Kamel Metwally ${ }^{1}$, Abdalla A. El-Shanawani ${ }^{1}$, Lobna M. Abdel-Aziz ${ }^{1}$, Harris Pratsinis ${ }^{2}$ \\ and Dimitris Kletsas
}

\begin{abstract}
Background: Rhodanines and quinazolinones have been reported to possess various pharmacological activities.

Results: A novel series of twenty quinazolinone-based rhodanines were synthesized via Knoevenagel condensation between 4-[3-(substitutedphenyl)-3,4-dihydro-4-oxoquinazolin-2-yl)methoxy]substituted-benzaldehydes and rhodanine. Elemental and spectral analysis were used to confirm structures of the newly synthesized compounds. The newly synthesized compounds were biologically evaluated for in vitro cytotoxic activity against the human fibrosarcoma cell line HT-1080 as a preliminary screen using the MTT assay.

Conclusions: All the target compounds were active, displaying $I C_{50}$ values roughly in the range of 10-60 $\mu \mathrm{M}$. Structure-activity relationship study revealed that bulky, hydrophobic, and electron withdrawing substituents at the paraposition of the quinazolinone 3-phenyl ring as well as methoxy substitution on the central benzene ring, enhance cytotoxic activity. The four most cytotoxic compounds namely, $\mathbf{4 5}, \mathbf{4 3}, \mathbf{4 7}$, and $\mathbf{3 7}$ were further tested against two human leukemia cell lines namely, $\mathrm{HL}-60$ and $\mathrm{K}-562$ and showed cytotoxic activity in the low micromolar range with compound $\mathbf{4 5}$ being the most active, having $\mathrm{IC}_{50}$ values of 1.2 and $1.5 \mu \mathrm{M}$, respectively. Interestingly, all four compounds were devoid of cytotoxicity against normal human fibroblasts strain AG01523, indicating that the synthesized rhodanines may be selectively toxic against cancer cells. Mechanistic studies revealed that the most cytotoxic target compounds exhibit pro-apoptotic activity and trigger oxidative stress in cancer cells.
\end{abstract}

Keywords: Rhodanines, Anticancer, Apoptosis, Reactive oxygen species

\section{Introduction}

Cancer is still one of the leading causes of death worldwide and the pursuit of novel clinically useful anticancer agents is therefore, one of the top priorities for medicinal chemists. Although gaining a reputation in recent years as "frequent hitters" in screening programs, rhodanines as well as their bioisosteres, 2,4-thiazolidinediones and the hydantoins, remain attractive tools to medicinal chemists for structural manipulations directed at developing potent and selective ligands for a wide array of potential molecular targets. There has been a growing debate in the medicinal chemistry community in the last

\footnotetext{
*Correspondence: shelsayed2013@gmail.com

1 Department of Medicinal Chemistry, Faculty of Pharmacy, Zagazig University, Zagazig, Egypt

Full list of author information is available at the end of the article
}

few years about the usefulness of rhodanines and related compounds as scaffolds or templates in drug discovery and drug development. In a recent comparative study on the rhodanines and related heterocycles, it was concluded that such scaffolds can serve as attractive building blocks rather than being promiscuous binders or multitarget chemotypes [1]. In the drug market, epalrestat is a rhodanineacetic acid derivative marketed in Japan since 1992 for the treatment of diabetic peripheral neuropathy. It acts by inhibiting aldose reductase which is the key enzyme in the polyol pathway of glucose metabolism under hyperglycemic conditions. Epalrestat was reported to be generally well tolerated on long-term use and it causes only few adverse effects such as nausea, vomiting and elevation of liver enzyme levels [2-7]. From a positive perspective, the good clinical safety profile of epalrestat justified our interest in rhodanines as potential 
therapeutic candidates. Literature survey revealed extensive research work on the anticancer effects of rhodanines over the last few decades [8-30]. On the molecular level, rhodanines were found to induce apoptosis through modulation of the pro-survival proteins of the Bcl-2 family [8-12] or through modulation of other key signaling proteins [13-16]. Interestingly, reactive oxygen species (ROS) have been reported to be up-regulated after rhodanine treatment, a fact possibly associated with mitochondria-mediated apoptosis [14, 29, 30]. Rhodanines were also reported to exert their anticancer effects through inhibition of phosphatase of regenerating liver (PRL-3) [16, 17]. On the other hand, numerous reports of quinazolinones as anticancer agents have appeared in literature [31-35]. Based on these findings, we were interested in investigating the anticancer effects of this novel scaffold of quinazolinone-based rhodanines, being isosteric to our previously reported 2,4-thiazolidindediones. In the present investigation, a series of twenty quinazolinone-based rhodanines were synthesized and tested for in vitro cytotoxic activity against the human fibrosarcoma cell line HT-1080 using the MTT assay. The four most active compounds namely, 45, 43, 47, and 37 were selected for further testing against two human leukemia cell lines (HL-60 and K-562) and the normal human fibroblasts strain AG01523, and their mechanism of action was investigated.

\section{Results and discussion}

\section{Chemistry}

A straight forward synthetic pathway was adopted to synthesize the target compounds $\mathbf{3 1 - 5 0}$ as depicted in Scheme 1. The intermediate chloromethylquinazolinones (1-10) were prepared following reported procedures from anthranilic acid in two steps [36-39]. The $\mathrm{N}$-chloroacetylation step was effected through reaction of anthranilic acid with chloroacetyl chloride in dry benzene under reflux conditions. The cyclization step was achieved by condensing the $N$-chloroacetyl derivatives with the appropriate anilines in presence of phosphorous oxychloride in dry toluene. Reaction of chloromethylquinazolinones (1-10) with 4-hydroxybenzaldehyde or vanillin under the basic conditions of potassium carbonate in the presence of potassium iodide to catalyze the alkylation, afforded the aldehyde derivatives (11-30) in good yields as previously reported by us [40]. Finally, the desired title rhodanines (31-50) were obtained by treatment of the aldehydes with rhodanine under Knoevenagel condensation conditions using sodium acetate as a catalyst. The target compounds were structurally characterized by means of ${ }^{1} \mathrm{H}$ NMR and ${ }^{13} \mathrm{C}$ NMR spectrometric methods. Characteristically, the rhodanine $\mathrm{NH}$ proton appeared at $13.75-13.77 \mathrm{ppm}$ as a broad singlet. The azomethine proton appeared within the aromatic region as a sharp singlet around $7.57 \mathrm{ppm}$. In ${ }^{13} \mathrm{C}$ NMR<smiles>[R]c1ccc(-n2c(COc3ccc(C=O)cc3[R2])nc3ccccc3c2=O)cc1</smiles>

(b)

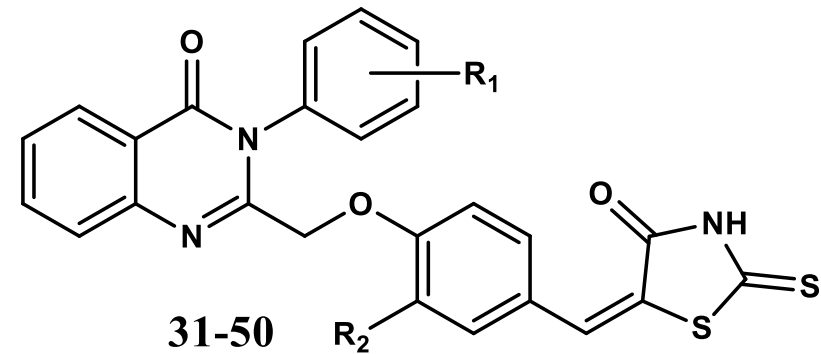

Scheme 1 Reagents and conditions: a 4-hydroxybenzaldehyde or vanillin, $\mathrm{K}_{2} \mathrm{CO}_{3}, \mathrm{Kl}$, acetonitrile, reflux, $3 \mathrm{~h}$. b Rhodanine, sodium acetate, glacial acetic acid, reflux, 24-48 $\mathrm{h}$ 
spectra, the thiocarbonyl carbon appeared in the range of 195-196 ppm. Compounds having trifluoromethyl groups namely, 37 and 47 , showed two characteristic quartets due to $\mathrm{C}-\mathrm{F}$ coupling. Other aliphatic and aromatic carbons appeared at their expected chemical shifts. The purity of the target compounds was satisfactorily confirmed by elemental analysis.

\section{Biological study}

The target compounds were initially screened for their in vitro cytotoxic activities against the human fibrosarcoma cell line HT-1080 using the MTT assay. As shown in Table 1, all compounds were active, and their $\mathrm{IC}_{50}$ values were roughly in the region between 10 and $60 \mu \mathrm{M}$. Close inspection of biological data of the tested compounds led to several observations on their structure-activity relationships. The best cytotoxic activity was displayed by compounds bearing a bulky, hydrophobic, and electron-withdrawing substituent at the para-position of the quinazolinone 3-phenyl ring as evidenced by the relatively low $\mathrm{IC}_{50}$ values of compounds $45\left(\mathrm{R}_{1}=4-\mathrm{Br}, \mathrm{R}_{2}=\mathrm{OCH}_{3} ; \mathrm{IC}_{50}=8.7 \mu \mathrm{M}\right), 43$ $\left(\mathrm{R}_{1}=4-\mathrm{Cl}, \mathrm{R}_{2}=\mathrm{OCH}_{3} ; \mathrm{IC}_{50}=10.2 \mu \mathrm{M}\right), 47\left(\mathrm{R}_{1}=4-\mathrm{CF}_{3}\right.$, $\left.\mathrm{R}_{2}=\mathrm{OCH}_{3} ; \mathrm{IC}_{50}=15.8 \mu \mathrm{M}\right)$, and $37\left(\mathrm{R}_{1}=4-\mathrm{CF}_{3}\right.$, $\left.\mathrm{R}_{2}=\mathrm{H} ; \mathrm{IC}_{50}=15.8 \mu \mathrm{M}\right)$. As a general pattern, meta-substituted compounds were found less active as compared to their para-substituted counterparts. Moreover, methoxy substitution on the central benzene ring appears to enhance cytotoxicity as evidenced by the lower $\mathrm{IC}_{50}$ values of compounds 41-50 in comparison to their unsubstituted analogues 31-40. The four most cytotoxic compounds were selected for further testing, starting with their cytotoxicity against two human leukemia cell lines (HL-60 and K-562) and the normal human skin fibroblast strain AG01523. As shown in Table 2, the leukemia cells were more sensitive to all four compounds, compared to HT-1080 cells, and compound 45 was again the most active compound, with $\mathrm{IC}_{50}$ values 1.2 and $1.5 \mu \mathrm{M}$, for HL-60 and K-562 cells, respectively. Other compounds tested displayed three to fourfold lower activity against the two cell lines tested. Interestingly, normal human fibroblasts were not affected by all four compounds, indicating that the synthesized rhodanines may be selectively toxic against cancer cells.

Regarding the mechanistic aspects of the above cytotoxic activity, flow cytometric analysis of DNA content did not reveal significant changes in the cell cycle phase distribution of rhodanine-treated HT-1080 cells compared with control ones, with the exception of an S-phase arrest caused by compounds $\mathbf{4 3}$ and 45 at $48 \mathrm{~h}$ (not shown). All four compounds were found to induce apoptosis of HL-60 cells, based on caspase-3 cleavage (Fig. 1), in accordance with the numerous literature reports
Table 1 Cytotoxicity of test compounds against HT-1080 cells

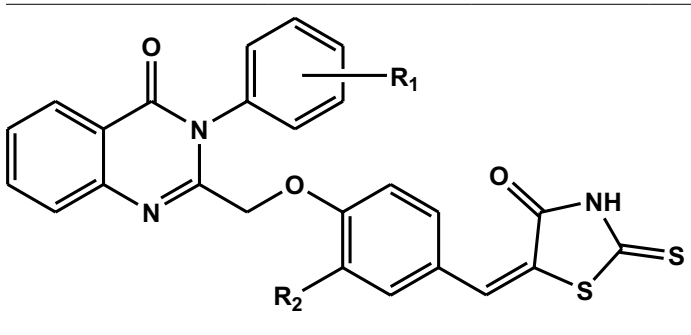

\begin{tabular}{lllc}
\hline Code & $\mathbf{R}_{\mathbf{1}}$ & $\mathbf{R}_{\mathbf{2}}$ & $\mathbf{H T}-\mathbf{1 0 8 0}$ \\
\hline $\mathbf{3 1}$ & $\mathrm{H}$ & $\mathrm{H}$ & $42.9( \pm 17.3)$ \\
$\mathbf{3 2}$ & $4-\mathrm{F}$ & $\mathrm{H}$ & $47.3( \pm 0.3)$ \\
$\mathbf{3 3}$ & $4-\mathrm{Cl}$ & $\mathrm{H}$ & $35.3( \pm 4.6)$ \\
$\mathbf{3 4}$ & $3-\mathrm{Cl}$ & $\mathrm{H}$ & $57.1( \pm 9.2)$ \\
$\mathbf{3 5}$ & $4-\mathrm{Br}$ & $\mathrm{H}$ & $28.8( \pm 2.4)$ \\
$\mathbf{3 6}$ & $3-\mathrm{Br}$ & $\mathrm{H}$ & $43.4( \pm 6.7)$ \\
$\mathbf{3 7}$ & $4-\mathrm{CF}_{3}$ & $\mathrm{H}$ & $15.8( \pm 2.1)$ \\
$\mathbf{3 8}$ & $4-\mathrm{CH}_{3}$ & $\mathrm{H}$ & $35.7( \pm 5.9)$ \\
$\mathbf{3 9}$ & $3-\mathrm{CH}_{3}$ & $\mathrm{H}$ & $47.5( \pm 12.1)$ \\
$\mathbf{4 0}$ & $4-\mathrm{OCH}_{3}$ & $\mathrm{H}$ & $36.4( \pm 0.9)$ \\
$\mathbf{4 1}$ & $\mathrm{H}$ & $\mathrm{OCH}_{3}$ & $36.1( \pm 2.9)$ \\
$\mathbf{4 2}$ & $4-\mathrm{F}$ & $\mathrm{OCH}_{3}$ & $35.8( \pm 11.8)$ \\
$\mathbf{4 3}$ & $4-\mathrm{Cl}$ & $\mathrm{OCH}_{3}$ & $10.2( \pm 4.7)$ \\
$\mathbf{4 4}$ & $3-\mathrm{Cl}$ & $\mathrm{OCH}_{3}$ & $28.4( \pm 9.4)$ \\
$\mathbf{4 5}$ & $4-\mathrm{Br}$ & $\mathrm{OCH}_{3}$ & $8.7( \pm 3.6)$ \\
$\mathbf{4 6}$ & $3-\mathrm{Br}$ & $\mathrm{OCH}_{3}$ & $23.7( \pm 0.6)$ \\
$\mathbf{4 7}$ & $4-\mathrm{CF}_{3}$ & $\mathrm{OCH}_{3}$ & $15.8( \pm 2.1)$ \\
$\mathbf{4 8}$ & $4-\mathrm{CH}_{3}$ & $\mathrm{OCH}_{3}$ & $31.5( \pm 4.1)$ \\
$\mathbf{4 9}$ & $3-\mathrm{CH}_{3}$ & $\mathrm{OCH}_{3}$ & $30.7( \pm 1.1)$ \\
$\mathbf{5 0}$ & $4-\mathrm{OCH}_{3}$ & $\mathrm{OCH}_{3}$ & $34.7( \pm 2.7)$ \\
Doxorubicin & - & - & $0.012( \pm 0.005)$ \\
\hline
\end{tabular}

$\mathrm{IC}_{50} \mathrm{~S}(\mu \mathrm{M})$, mean of three independent experiments ( \pm standard deviation)

[8-16, 29, 30]. Furthermore, all four compounds were found to significantly induce intracellular ROS accumulation in HT-1080 cells following a 48-h treatment (Fig. 2), in agreement with similar observations in other cancer cell lines using different rhodanine molecules $[29,30]$.

\section{Experimental \\ Chemistry \\ General}

Melting points are uncorrected and were measured on a Gallenkamp melting point apparatus. ${ }^{1} \mathrm{H}$ and ${ }^{13} \mathrm{C}$ NMR spectra were recorded on Bruker $400-\mathrm{MHz}$, JEOL RESONANCE $500-\mathrm{MHz}$, and Varian-Mercury 300$\mathrm{MHz}$ spectrometers. Chemical shifts were expressed in parts per million (ppm) downfield from tetramethylsilane (TMS) and coupling constants $(J)$ were reported 
Table 2 Cytotoxicity of selected compounds against a panel of cell strains

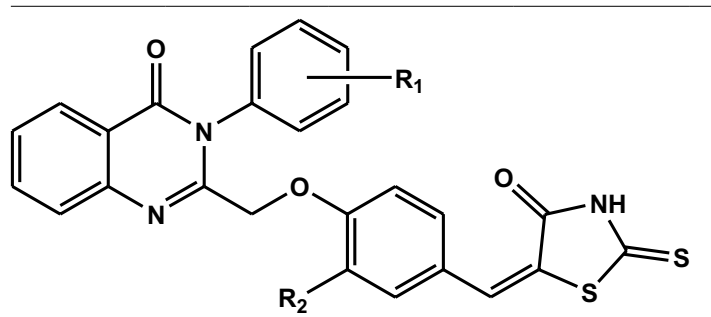

\begin{tabular}{llllll}
\hline Code & $\mathbf{R}_{\mathbf{1}}$ & $\mathbf{R}_{\mathbf{2}}$ & \multicolumn{2}{l}{ Cell line } \\
\cline { 4 - 6 } & & & HL-60 & \multicolumn{1}{l}{ K-562 } & AG01523 \\
\hline $\mathbf{3 7}$ & $4-\mathrm{CF}_{3}$ & $\mathrm{H}$ & $5.5( \pm 0.2)$ & $5.0( \pm 3.2)$ & $>100$ \\
$\mathbf{4 3}$ & $4-\mathrm{Cl}$ & $\mathrm{OCH}_{3}$ & $5.1( \pm 2.0)$ & $4.5( \pm 4.3)$ & $>100$ \\
$\mathbf{4 5}$ & $4-\mathrm{Br}$ & $\mathrm{OCH}_{3}$ & $1.2( \pm 0.5)$ & $1.5( \pm 0.2)$ & $>100$ \\
$\mathbf{4 7}$ & $4-\mathrm{CF}_{3}$ & $\mathrm{OCH}_{3}$ & $2.6( \pm 0.4)$ & $5.1( \pm 0.3)$ & $>100$ \\
Doxorubicin & - & - & $0.011( \pm 0.006)$ & $0.212( \pm 0.074)$ & 0.875 \\
& & & & \multicolumn{3}{c}{$( \pm 0.248)$}
\end{tabular}

$\mathrm{IC}_{50} \mathrm{~S}(\mu \mathrm{M})$, mean of three independent experiments ( \pm standard deviation)

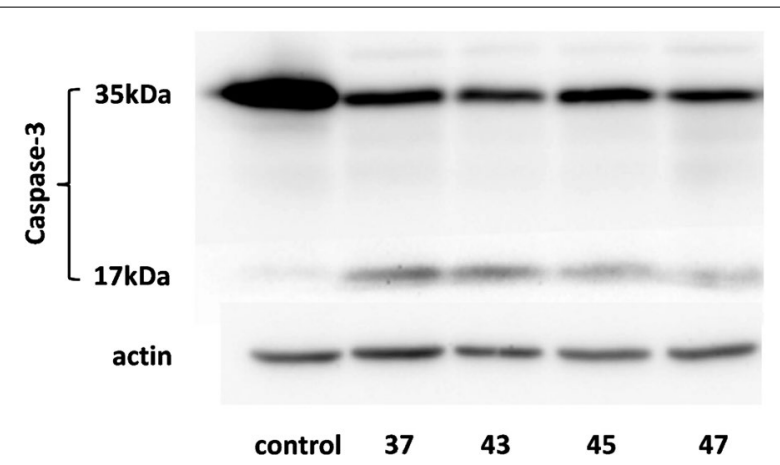

Fig. 1 Apoptosis of HL-60 cells following rhodanine treatment. Cells incubated with the indicated compounds $(50 \mu \mathrm{M})$ or the corresponding concentration of vehicle (control) for $48 \mathrm{~h}$ were lysed, and caspase-3 cleavage was monitored by Western analysis of cell lysates (one representative experiment out of two similar ones is depicted)

in Hertz. Elemental analyses $(\mathrm{C}, \mathrm{H}, \mathrm{N})$ were performed at the Microanalytical Unit, Cairo university, and the Regional Center for Mycology and Biotechnology, Al-Azhar University, Cairo, Egypt. All compounds were routinely checked by thin-layer chromatography (TLC) on aluminum-backed silica gel plates. Flash column chromatography was performed using silica gel (100-200 mesh) with the indicated solvents. All solvents used in this study were dried by standard methods. The starting 2-(chloromethyl)-3-(substitutedphenyl) quinazolin-4(3H)-ones $\quad(\mathbf{1}-\mathbf{1 0}) \quad$ [36-39] and 4-[3-(substitutedphenyl)-3,4-dihydro-4-oxoquinazolin2-yl)methoxy] substitutedbenzaldehydes (11-30) [40] were synthesized following reported procedures.

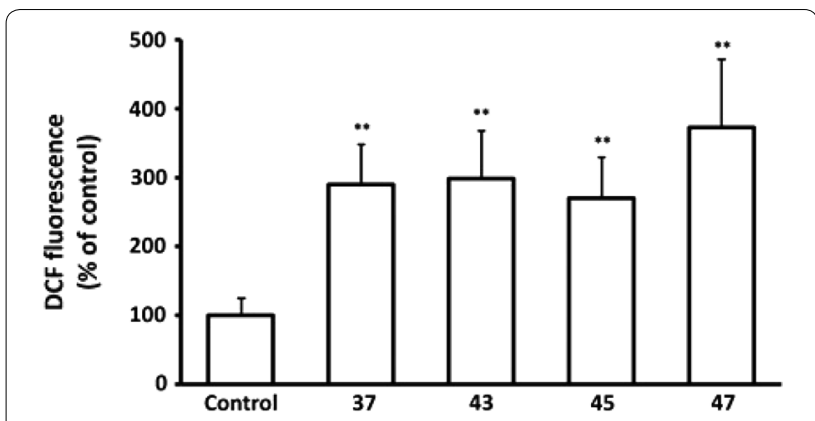

Fig. 2 Oxidative stress of HT-1080 cells following rhodanine treatment. Cells were incubated with the indicated compounds $(10 \mu \mathrm{M})$ or the corresponding concentration of vehicle (control). Intracellular ROS were determined after 48 h using the DCFH-DA method. Results represent the mean \pm standard deviation of three independent experiments $\left({ }^{* *} p<0.01\right)$

\section{Synthetic procedures}

General procedure for the synthesis of 5-\{4-[(3-substitutedphenyl-4-oxo-3,4-dihydroquinazolin-2-yl)methoxy] substitutedbenzylidene\}-2-thioxothiazolidin-4-ones 3150 A mixture of the appropriate aldehyde $(10 \mathrm{mmol})$, rhodanine $(20 \mathrm{mmol})$, and sodium acetate $(20 \mathrm{mmol})$ in glacial acetic acid $(10 \mathrm{ml})$, was heated under reflux for $48 \mathrm{~h}$. After cooling to room temperature, the reaction mixture was poured into water and the precipitate was filtered, washed with water and dried. The crude product was subjected to silica gel column chromatography using methylene chloride/methanol (99:1) as an eluent followed by recrystallization from $\mathrm{DMF} / \mathrm{EtOH}$ or $\mathrm{DMF} / \mathrm{H}_{2} \mathrm{O}$.

5-\{4-[(3-Phenyl-4-oxo-3,4-dihydroquinazolin-2-yl)methoxy]benzylidene\}-2-thioxothiazolidin-4-one (31) Yield: $54 \%$, mp 230-232 ${ }^{\circ} \mathrm{C}$ (DMF/EtOH); ${ }^{1} \mathrm{H}$ NMR (DMSO$\left.\mathrm{d}_{6}, \mathrm{ppm}\right): \delta 4.83\left(\mathrm{~s}, 2 \mathrm{H}, \mathrm{CH}_{2}\right), 6.99-7.03(\mathrm{~m}, 2 \mathrm{H}, \mathrm{Ar}-\mathrm{H})$, 7.43-7.62 (m, 9H, Ar-H, azomethine-H), 7.70-7.72 (d, $J=800 \mathrm{~Hz}, 1 \mathrm{H}, \mathrm{Ar}-\mathrm{H}), 7.86-7.88(\mathrm{~m}, 1 \mathrm{H}, \mathrm{Ar}-\mathrm{H}), 8.15-$ $8.17\left(\mathrm{dd}, J_{1}=1.20 \mathrm{~Hz}, J_{2}=8.00 \mathrm{~Hz}, 1 \mathrm{H}, \mathrm{Ar}-\mathrm{H}\right), 13.75$ (s, 1H, NH). ${ }^{13} \mathrm{C}$ NMR (DMSO-d $\left.6, \mathrm{ppm}\right): \delta 67.75\left(\mathrm{CH}_{2}\right)$, 115.61 (2C), 121.06, 122.64, 126.05, 126.42, 127.37, 127.57, 128.71 (2C), 129.19, $129.28(2 \mathrm{C}), 131.59,132.42$ (2C), 134.83, 135.88, 146.66, 151.07, 159.45, 161.16, 169.41, $195.48(\mathrm{C}=\mathrm{S})$. Anal. calcd for $\mathrm{C}_{25} \mathrm{H}_{17} \mathrm{~N}_{3} \mathrm{O}_{3} \mathrm{~S}_{2}: \mathrm{C}$, 63.68; H, 3.63; N, 8.91. Found: C, 63.55; H, 3.88; N, 8.60.

5-\{4-[(3-(4-Fluorophenyl)-4-oxo-3,4-dihydroquinazolin-2-yl)methoxy] benzylidene\}-2-thioxothiazolidin-4-one (32) Yield: $46 \%$, mp $231-233{ }^{\circ} \mathrm{C}$, dec. $\left(\mathrm{DMF} / \mathrm{H}_{2} \mathrm{O}\right) ;{ }^{1} \mathrm{H}$ NMR (DMSO-d $\left.{ }_{6}, \mathrm{ppm}\right): \delta 4.86\left(\mathrm{~s}, 2 \mathrm{H}, \mathrm{CH}_{2}\right), 7.02-7.04(\mathrm{~d}$, $J=8.80 \mathrm{~Hz}, 2 \mathrm{H}, \mathrm{Ar}-\mathrm{H}), 7.33-7.38$ (m, 2H, Ar-H), 7.50$7.52(\mathrm{~d}, J=8.80 \mathrm{~Hz}, 2 \mathrm{H}, \mathrm{Ar}-\mathrm{H}), 7.59(\mathrm{~s}, 1 \mathrm{H}$, azomethine$\mathrm{H})$, 7.61-7.65 (m, 3H, Ar-H), 7.71-7.73 (d, $J=8.00 \mathrm{~Hz}$, 
$1 \mathrm{H}, \operatorname{Ar}-\mathrm{H}), 7.87-7.91(\mathrm{~m}, 1 \mathrm{H}, \operatorname{Ar}-\mathrm{H}), 8.16-8.18(\mathrm{~d}$, $J=7.60 \mathrm{~Hz}, 1 \mathrm{H}, \mathrm{Ar}-\mathrm{H}), 13.76(\mathrm{~s}, 1 \mathrm{H}, \mathrm{NH}) .{ }^{13} \mathrm{C} \mathrm{NMR}$ (DMSO-d $\left.{ }_{6}, \mathrm{ppm}\right): \delta 68.28\left(\mathrm{CH}_{2}\right), 116.13(2 \mathrm{C}), 116.55$, $116.78,121.49,123.17,126.58,126.92,127.86,128.12$, $131.49(\mathrm{~d}, J=9.0 \mathrm{~Hz}), 132.09,132.52,132.92(2 \mathrm{C}), 135.39$, $147.10,151.59,159.91,161.30,161.78,163.75,169.92$, $195.97(\mathrm{C}=\mathrm{S})$. Anal. calcd for $\mathrm{C}_{25} \mathrm{H}_{16} \mathrm{FN}_{3} \mathrm{O}_{3} \mathrm{~S}_{2}$ : C, 61.34; H, 3.29; N, 8.58. Found: C, 61.27; H, 3.63; N, 8.51.

5-\{4-[(3-(4-Chlorophenyl)-4-oxo-3,4-dihydroquinazolin-2-yl)methoxy]benzylidene\}-2-thioxothiazolidin-4-one (33) Yield: 51\%, mp $121-123{ }^{\circ} \mathrm{C}\left(\mathrm{DMF} / \mathrm{H}_{2} \mathrm{O}\right) ;{ }^{1} \mathrm{H}$ NMR (DMSO-d $\left.\mathrm{d}_{6}, \mathrm{ppm}\right): \delta 4.88\left(\mathrm{~s}, 2 \mathrm{H}, \mathrm{CH}_{2}\right), 7.01-7.03$ $(\mathrm{d}, J=8.00 \mathrm{~Hz}, 2 \mathrm{H}, \mathrm{Ar}-\mathrm{H}), 7.48-7.50(\mathrm{~d}, J=8.00 \mathrm{~Hz}$, $2 \mathrm{H}, \mathrm{Ar}-\mathrm{H}), 7.57-7.58(\mathrm{~m}, 6 \mathrm{H}, \mathrm{Ar}-\mathrm{H}$, azomethine- $\mathrm{H})$, $7.70-7.72(\mathrm{~d}, J=8.00 \mathrm{~Hz}, 1 \mathrm{H}, \mathrm{Ar}-\mathrm{H}), 7.86-7.90(\mathrm{~m}, 1 \mathrm{H}$, Ar-H), 8.15-8.17 (d, $J=7.60 \mathrm{~Hz}, 1 \mathrm{H}, \mathrm{Ar}-\mathrm{H}), 13.76(\mathrm{~s}$, $1 \mathrm{H}, \mathrm{NH}) .{ }^{13} \mathrm{C}$ NMR (DMSO-d $\left.6, \mathrm{ppm}\right): \delta 68.28\left(\mathrm{CH}_{2}\right)$, 116.14 (2C), 121.46, 123.19, 126.61, 126.93, 127.88, $128.16,129.84(2 \mathrm{C}), 131.22$ (2C), 132.09, $132.91(2 \mathrm{C})$, $134.35,135.29,135.43,147.08,151.35,159.87,161.66$, 169.92, $195.98(\mathrm{C}=\mathrm{S})$. Anal. calcd for $\mathrm{C}_{25} \mathrm{H}_{16} \mathrm{ClN}_{3} \mathrm{O}_{3} \mathrm{~S}_{2}$ : C, 59.34; H, 3.19; N, 8.30. Found: C, 58.90; H, 3.59; N, 8.29.

5-\{4-[(3-(3-Chlorophenyl)-4-oxo-3,4-dihydroquinazolin-2-yl)methoxy]benzylidene -2-thioxothiazolidin-4-one (34) Yield: $55 \%, \mathrm{mp} 237-239{ }^{\circ} \mathrm{C}\left(\mathrm{DMF} / \mathrm{H}_{2} \mathrm{O}\right) ;{ }^{1} \mathrm{H}$ NMR (DMSO-d ${ }_{6}, \mathrm{ppm}$ ): $\delta 4.89\left(\mathrm{~s}, 2 \mathrm{H}, \mathrm{CH}_{2}\right), 7.01-7.03(\mathrm{~m}, 2 \mathrm{H}$, Ar-H), 7.49-7.64 (m, 7H, Ar-H, azomethine-H), 7.727.75 (m, 2H, Ar-H), 7.88-7.92 (m, 1H, Ar-H), 8.16-8.18 $\left(\mathrm{dd}, J_{1}=1.20 \mathrm{~Hz}, J_{2}=8.00 \mathrm{~Hz}, 1 \mathrm{H}, \mathrm{Ar}-\mathrm{H}\right), 13.76(\mathrm{~s}, 1 \mathrm{H}$, NH). ${ }^{13} \mathrm{C}$ NMR (DMSO-d 6 , ppm): $\delta 67.87\left(\mathrm{CH}_{2}\right), 115.60$ (2C), 121.00, 122.75, 126.14, 126.43, 127.41, 127.69 (2C), $129.09,129.28,130.75,131.54,132.39$ (2C), 133.34, 134.94, 137.24, 146.57, 150.69, 159.34, 161.10, 169.47, $195.49(\mathrm{C}=\mathrm{S})$. Anal. Calcd for $\mathrm{C}_{25} \mathrm{H}_{16} \mathrm{ClN}_{3} \mathrm{O}_{3} \mathrm{~S}_{2}$ : C, 59.34; $\mathrm{H}, 3.19$; N, 8.30. Found: C, 59.47; H, 3.44; N, 8.22.

5-\{4-[(3-(4-Bromophenyl)-4-oxo-3,4-dihydroquinazolin-2-yl)methoxy]benzylidene\}-2-thioxothiazolidin-4-one (35) Yield: 52\%, mp $171-174{ }^{\circ} \mathrm{C}\left(\mathrm{DMF} / \mathrm{H}_{2} \mathrm{O}\right) ;{ }^{1} \mathrm{H}$ NMR (DMSO-d $\left.{ }_{6}, \mathrm{ppm}\right): \delta 4.88\left(\mathrm{~s}, 2 \mathrm{H}, \mathrm{CH}_{2}\right), 7.01-7.03$ $(\mathrm{d}, J=8.40 \mathrm{~Hz}, 2 \mathrm{H}, \mathrm{Ar}-\mathrm{H}), 7.49-7.54(\mathrm{~m}, 4 \mathrm{H}, \mathrm{Ar}-\mathrm{H})$, 7.58-7.62 (m, 2H, Ar-H, azomethine-H), 7.70-7.72 (d, $J=8.40 \mathrm{~Hz}, 3 \mathrm{H}, \mathrm{Ar}-\mathrm{H}), 7.86-7.90(\mathrm{t}, J=7.60 \mathrm{~Hz}, 1 \mathrm{H}$, Ar-H), 8.14-8.16 (d, $J=8.00 \mathrm{~Hz}, 1 \mathrm{H}, \mathrm{Ar}-\mathrm{H}), 13.75(\mathrm{~s}$, $1 \mathrm{H}, \mathrm{NH}) .{ }^{13} \mathrm{C}$ NMR (DMSO-d $\left.6, \mathrm{ppm}\right): \delta 68.27\left(\mathrm{CH}_{2}\right)$, 116.17 (2C), 121.47, 122.97, 123.16, 126.61, 126.92, $127.89,128.13,131.52$ (2C), 132.11, 132.80 (2C), 132.91 (2C), 135.41, 135.76, 147.09, 151.30, 159.89, 161.60, 169.89, $195.96(\mathrm{C}=\mathrm{S})$. Anal. calcd for $\mathrm{C}_{25} \mathrm{H}_{16} \mathrm{BrN}_{3} \mathrm{O}_{3} \mathrm{~S}_{2}$ : C, 54.55; H, 2.93; N, 7.63. Found: C, 54.19; H, 3.20; N, 7.49.
5-\{4-[(3-(3-Bromophenyl)-4-oxo-3,4-dihydroquinazolin-2-yl)methoxy]benzylidene\}-2-thioxothiazolidin-4-one (36) Yield: 48\%, mp $252-254 \quad{ }^{\circ} \mathrm{C} \quad\left(\mathrm{DMF} / \mathrm{H}_{2} \mathrm{O}\right) ;{ }^{1} \mathrm{H}$ NMR (DMSO- $\mathrm{d}_{6}, \mathrm{ppm}$ ): $\delta 4.88\left(\mathrm{~s}, 2 \mathrm{H}, \mathrm{CH}_{2}\right), 7.00-7.02$ $(\mathrm{d}, J=8.80 \mathrm{~Hz}, 2 \mathrm{H}, \mathrm{Ar}-\mathrm{H}), 7.43-7.51(\mathrm{~m}, 3 \mathrm{H}, \mathrm{Ar}-\mathrm{H})$, 7.57-7.64 (m, 4H, Ar-H, azomethine-H), 7.71-7.73 (d, $J=8.00 \mathrm{~Hz}, 1 \mathrm{H}, \mathrm{Ar}-\mathrm{H}), 7.86-7.91(\mathrm{~m}, 2 \mathrm{H}, \mathrm{Ar}-\mathrm{H})$, 8.15-8.17 (d, $J=8.00 \mathrm{~Hz}, 1 \mathrm{H}, \mathrm{Ar}-\mathrm{H}), 13.75(\mathrm{~s}, 1 \mathrm{H}, \mathrm{NH})$. ${ }^{13} \mathrm{C}$ NMR (DMSO-d $\left.\mathrm{d}_{6}, \mathrm{ppm}\right): \delta 68.41\left(\mathrm{CH}_{2}\right), 116.10(2 \mathrm{C})$, $121.51,122.05,123.37,126.67,126.93,127.91,128.20$, $128.53,131.50,131.95,132.36,132.64,132.87$ (2C), $135.44,137.85,147.06,151.19,159.80,161.62,170.11$, $196.07(\mathrm{C}=\mathrm{S})$. Anal. Calcd for $\mathrm{C}_{25} \mathrm{H}_{16} \mathrm{BrN}_{3} \mathrm{O}_{3} \mathrm{~S}$ : C, 54.55; H, 2.93; N, 7.63. Found: C, 54.72; H, 3.08; N, 7.53.

5-\{4-[(3-(4-Trifluoromethylphenyl)-4-oxo-3,4-dihydroquinazolin-2-yl)methoxy]benzylidene $\}$-2-thioxothiazolidin-4-one (37) Yield: $38 \%, \mathrm{mp} 153-155^{\circ} \mathrm{C}\left(\mathrm{DMF} / \mathrm{H}_{2} \mathrm{O}\right)$; ${ }^{1} \mathrm{H}$ NMR (DMSO-d ${ }_{6}, \mathrm{ppm}$ ): $\delta 4.89\left(\mathrm{~s}, 2 \mathrm{H}, \mathrm{CH}_{2}\right), 6.96-6.99$ (d, $J=8.80 \mathrm{~Hz}, 2 \mathrm{H}, \mathrm{Ar}-\mathrm{H}), 7.47-7.49(\mathrm{~d}, J=8.80 \mathrm{~Hz}$, $2 \mathrm{H}, \mathrm{Ar}-\mathrm{H}), 7.57(\mathrm{~s}, 1 \mathrm{H}$, azomethine-H), 7.61-7.65 (m, $1 \mathrm{H}, \mathrm{Ar}-\mathrm{H}), 7.72-7.81(\mathrm{~m}, 3 \mathrm{H}, \mathrm{Ar}-\mathrm{H}), 7.90-7.93(\mathrm{~m}, 2 \mathrm{H}$, $\mathrm{Ar}-\mathrm{H}), 8.04(\mathrm{~s}, 1 \mathrm{H}, \mathrm{Ar}-\mathrm{H}), 8.17-8.18(\mathrm{~d}, J=7.20 \mathrm{~Hz}, 1 \mathrm{H}$, $\mathrm{Ar}-\mathrm{H}), 13.76$ (s, $1 \mathrm{H}, \mathrm{NH}) .{ }^{13} \mathrm{C}$ NMR (DMSO-d $\left.\mathrm{d}_{6}, \mathrm{ppm}\right): \delta$ $68.56\left(\mathrm{CH}_{2}\right), 115.92(2 \mathrm{C}), 121.52,122.79,123.24,125.50$, 126.47 (partially resolved q, $J=4.0 \mathrm{~Hz}$ ), $126.65,126.93$, 127. $93,128.28,130.31(\mathrm{q}, J=32.0 \mathrm{~Hz}), 130.96,132.03$, 132.84 (2C), 133.60, 135.50, 137.28, 147.06, 151.13, $159.65,161.76,169.88,195.96(\mathrm{C}=\mathrm{S})$. Anal. calcd for $\mathrm{C}_{26} \mathrm{H}_{16} \mathrm{~F}_{3} \mathrm{~N}_{3} \mathrm{O}_{3} \mathrm{~S}_{2}:$ C, 57.88; H, 2.99; N, 7.79. Found: C, $57.82 ; \mathrm{H}, 3.22 ; \mathrm{N}, 7.73$.

5-\{4-[(3-(4-Methylphenyl)-4-oxo-3,4-dihydroquinazolin-2-yl)methoxy]benzylidene $\}$-2-thioxothiazolidin-4-one (38) Yield: $51 \%$, mp $148-150{ }^{\circ} \mathrm{C}\left(\mathrm{DMF} / \mathrm{H}_{2} \mathrm{O}\right) ;{ }^{1} \mathrm{H}$ NMR (DMSO-d $\left.{ }_{6}, \mathrm{ppm}\right): \delta 2.08\left(\mathrm{~s}, 3 \mathrm{H}, \mathrm{CH}_{3}\right), 4.84\left(\mathrm{~s}, 2 \mathrm{H}, \mathrm{CH}_{2}\right)$, 6.99-7.02 (d, $J=8.70 \mathrm{~Hz}, 2 \mathrm{H}, \operatorname{Ar}-\mathrm{H}), 7.29-7.32(\mathrm{~d}$, $J=7.80 \mathrm{~Hz}, 2 \mathrm{H}, \mathrm{Ar}-\mathrm{H}), 7.37-7.42(\mathrm{~m}, 2 \mathrm{H}, \mathrm{Ar}-\mathrm{H}), 7.47-$ $7.50(\mathrm{~d}, J=8.70 \mathrm{~Hz}, 2 \mathrm{H}, \mathrm{Ar}-\mathrm{H}), 7.56-7.61(\mathrm{~m}, 2 \mathrm{H}, \mathrm{Ar}-\mathrm{H}$, azomethine-H), 7.67-7.70 (d, $J=8.10 \mathrm{~Hz}, 1 \mathrm{H}, \mathrm{Ar}-\mathrm{H})$, 7.83-7.88 (m, $1 \mathrm{H}, \mathrm{Ar}-\mathrm{H}), 8.14-8.16(\mathrm{~d}, J=8.10 \mathrm{~Hz}, 1 \mathrm{H}$, Ar-H), 13.75 (s, 1H, NH). ${ }^{13} \mathrm{C}$ NMR (DMSO-d 6 , ppm): $\delta 20.68\left(\mathrm{CH}_{3}\right), 67.62\left(\mathrm{CH}_{2}\right), 115.66(2 \mathrm{C}), 120.48,121.01$, 122.61, 126.01, 126.38, 127.31, 128.36 (2C), 129.78 (2C), 131.57, 132.38 (2C), 133.20, 134.73, 138.68, 146.63, 151.24, 159.52, 161.84, 169.36, 195.44 (C=S). Anal. Calcd for $\mathrm{C}_{26} \mathrm{H}_{19} \mathrm{~N}_{3} \mathrm{O}_{3} \mathrm{~S}_{2}$ : C, 64.31; H, 3.94; N, 8.65. Found: C, $63.98 ; \mathrm{H}, 3.71 ; \mathrm{N}, 8.80$.

5-\{4-[(3-(3-Methylphenyl)-4-oxo-3,4-dihydroquinazolin-2yl)methoxy]benzylidene\}-2-thioxothiazolidin-4-one (39) Yield: $54 \%, \mathrm{mp} 165-168{ }^{\circ} \mathrm{C}$ (DMF/EtOH); ${ }^{1} \mathrm{H}$ 
NMR (DMSO-d $\left.{ }_{6}, \mathrm{ppm}\right): \delta 2.31\left(\mathrm{~s}, 3 \mathrm{H}, \mathrm{CH}_{3}\right), 4.83(\mathrm{~s}, 2 \mathrm{H}$, $\left.\mathrm{CH}_{2}\right), 6.99-7.01(\mathrm{~d}, J=8.80 \mathrm{~Hz}, 2 \mathrm{H}, \mathrm{Ar}-\mathrm{H}), 7.23-7.25(\mathrm{~d}$, $J=7.60 \mathrm{~Hz}, 1 \mathrm{H}, \mathrm{Ar}-\mathrm{H}), 7.31-7.39$ (m, 3H, Ar-H), 7.48$7.50(\mathrm{~d}, J=8.80 \mathrm{~Hz}, 2 \mathrm{H}, \mathrm{Ar}-\mathrm{H}), 7.57(\mathrm{~s}, 1 \mathrm{H}$, azomethine$\mathrm{H}), 7.60-7.62(\mathrm{~d}, J=8.00 \mathrm{~Hz}, 1 \mathrm{H}, \mathrm{Ar}-\mathrm{H}), 7.70-7.72(\mathrm{~d}$, $J=8.00 \mathrm{~Hz}, 1 \mathrm{H}, \mathrm{Ar}-\mathrm{H}), 7.85-7.89(\mathrm{~m}, 1 \mathrm{H}, \mathrm{Ar}-\mathrm{H}), 8.14-$ $8.16\left(\mathrm{dd}, J_{1}=1.20 \mathrm{~Hz}, J_{2}=8.00 \mathrm{~Hz} 1 \mathrm{H}, \mathrm{Ar}-\mathrm{H}\right), 13.75$ (s, $1 \mathrm{H}, \mathrm{NH}) .{ }^{13} \mathrm{C}$ NMR (DMSO-d $\left.6, \mathrm{ppm}\right): \delta 20.73\left(\mathrm{CH}_{3}\right)$, $67.79\left(\mathrm{CH}_{2}\right), 115.60(2 \mathrm{C}), 121.05,122.73,125.55,126.06$, $126.40,127.37,127.58,129.05,129.21,129.77,131.54$, 132.39 (2C), 134.81, 135.73, 138.85, 146.64, 151.12, 159.47, 161.14, 169.53, $195.54(\mathrm{C}=\mathrm{S})$. Anal. Calcd for $\mathrm{C}_{26} \mathrm{H}_{19} \mathrm{~N}_{3} \mathrm{O}_{3} \mathrm{~S}_{2}$ : C, 64.31; H, 3.94; N, 8.65. Found: C, 64.00; $\mathrm{H}, 3.87$; N, 8.87.

5-\{4-[(3-(4-Methoxyphenyl)-4-oxo-3,4-dihydroquinazolin-2-yl)methoxy]benzylidene\}-2-thioxothiazolidin-4-one (40) Yield: $50 \%$, mp $190-192{ }^{\circ} \mathrm{C}$, dec. (DMF/EtOH); ${ }^{1} \mathrm{H}$ NMR (DMSO-d $\left.{ }_{6}, \mathrm{ppm}\right): \delta 3.78\left(\mathrm{~s}, 3 \mathrm{H}, \mathrm{OCH}_{3}\right), 4.85(\mathrm{~s}$, $2 \mathrm{H}, \mathrm{CH}_{2}$ ), 7.03-7.06 (dd, $J_{1}=3.20 \mathrm{~Hz} J_{2}=8.80 \mathrm{~Hz}, 4 \mathrm{H}$, Ar-H), 7.45-7.47 (d, $J=8.00 \mathrm{~Hz}, 2 \mathrm{H}, \mathrm{Ar}-\mathrm{H}), 7.50-7.52$ $(\mathrm{d}, J=8.80 \mathrm{~Hz}, 2 \mathrm{H}, \mathrm{Ar}-\mathrm{H}), 7.57-7.61(\mathrm{~m}, 2 \mathrm{H}, \mathrm{Ar}-\mathrm{H}$, azomethine-H), 7.68-7.70 (d, $J=8.00 \mathrm{~Hz}, 1 \mathrm{H}, \mathrm{Ar}-\mathrm{H})$, 7.85-7.89 (t, $J=7.20 \mathrm{~Hz}, 1 \mathrm{H}, \operatorname{Ar}-\mathrm{H}), 8.15-8.17(\mathrm{~d}$, $J=7.20 \mathrm{~Hz}, 1 \mathrm{H}, \mathrm{Ar}-\mathrm{H}), 13.76(\mathrm{~s}, 1 \mathrm{H}, \mathrm{NH}) .{ }^{13} \mathrm{C} \mathrm{NMR}$ (DMSO-d $\left.{ }_{6}, \mathrm{ppm}\right): \delta 55.34\left(\mathrm{OCH}_{3}\right), 67.66\left(\mathrm{CH}_{2}\right), 114.46$ (2C), 115.68 (2C), 120.41, 121.03, 122.60, 126.01, 126.38, $127.29,127.42,128.23,129.78$ (2C), 131.59, 132.39 (2C), $134.70,146.64,151.54,159.44,161.34,169.36,195.44$ $(\mathrm{C}=\mathrm{S})$. Anal. calcd for $\mathrm{C}_{26} \mathrm{H}_{19} \mathrm{~N}_{3} \mathrm{O}_{4} \mathrm{~S}_{2}: \mathrm{C}, 62.26 ; \mathrm{H}, 3.82$; N, 8.38. Found: C, 62.33; H, 3.92; N, 8.18.

5-\{4-[(3-Phenyl-4-oxo-3,4-dihydroquinazolin-2-yl)meth oxy]-3-methoxybenzylidene $\}$-2-thioxothiazolidin-4-one (41) Yield: $50 \%$, mp $243-246{ }^{\circ} \mathrm{C}\left(\mathrm{DMF} / \mathrm{H}_{2} \mathrm{O}\right) ;{ }^{1} \mathrm{H}$ NMR (DMSO-d $\left.\mathrm{d}_{6}, \mathrm{ppm}\right): \delta 3.83\left(\mathrm{~s}, 3 \mathrm{H}, \mathrm{OCH}_{3}\right), 4.79(\mathrm{~s}, 2 \mathrm{H}$, $\left.\mathrm{CH}_{2}\right), 6.94-6.96(\mathrm{~d}, J=8.40 \mathrm{~Hz}, 1 \mathrm{H}, \mathrm{Ar}-\mathrm{H}), 7.03-7.06$ $\left(\mathrm{dd}, J_{1}=1.60 \mathrm{~Hz}, J_{2}=8.40 \mathrm{~Hz}, 1 \mathrm{H}, \mathrm{Ar}-\mathrm{H}\right), 7.16(\mathrm{~m}, 1 \mathrm{H}$, Ar-H), 7.36-7.62 (m, 7H, Ar-H, azomethine-H), 7.70$7.72(\mathrm{~d}, J=8.00 \mathrm{~Hz}, 1 \mathrm{H}, \mathrm{Ar}-\mathrm{H}), 7.86-7.90(\mathrm{t}, J=7.60 \mathrm{~Hz}$, $1 \mathrm{H}, \mathrm{Ar}-\mathrm{H}), 8.15-8.17(\mathrm{~d}, J=8.00 \mathrm{~Hz}, 1 \mathrm{H}, \mathrm{Ar}-\mathrm{H}) .{ }^{13} \mathrm{C}$ NMR (DMSO-d $\left.\mathrm{d}_{6}, \mathrm{ppm}\right): \delta 55.69\left(\mathrm{OCH}_{3}\right), 68.35\left(\mathrm{CH}_{2}\right)$, 113.87, 113.94, 121.05, 122.86, 124.02, 126.41, 126.53, 127.39, 127.59, 128.77, 129.15 (2C), 131.95 (3C), 134.84, 135.79, 146.66, 149.19, 149.25, 151.12, 161.17, 169.36, 195.44 (C=S). Anal. calcd for $\mathrm{C}_{26} \mathrm{H}_{19} \mathrm{~N}_{3} \mathrm{O}_{4} \mathrm{~S}_{2}$ : C, 62.26; $\mathrm{H}$, 3.82; N, 8.38. Found: C, 62.17; H, 3.80; N, 8.12.

5-\{4-[(3-(4-Fluorophenyl)-4-oxo-3,4-dihydroquinazolin-2-yl)methoxy]-3-methoxybenzylidene $\}$-2-thioxothiazolidin-4-one (42) Yield: $49 \%, \mathrm{mp} 163-166{ }^{\circ} \mathrm{C}$ (DMF/ EtOH); ${ }^{1} \mathrm{H}$ NMR (DMSO-d $\left.{ }_{6}, \mathrm{ppm}\right): \delta 3.84\left(\mathrm{~s}, 3 \mathrm{H}, \mathrm{OCH}_{3}\right.$ ), $4.83\left(\mathrm{~s}, 2 \mathrm{H}, \mathrm{CH}_{2}\right), 6.99-7.01(\mathrm{~d}, J=8.40 \mathrm{~Hz}, 1 \mathrm{H}, \mathrm{Ar}-\mathrm{H})$,
7.06-7.08 (d, $J=8.40 \mathrm{~Hz}, 1 \mathrm{H}, \mathrm{Ar}-\mathrm{H}), 7.17(\mathrm{~s}, 1 \mathrm{H}, \mathrm{Ar}-\mathrm{H})$, 7.31-7.35 (m, 2H, Ar-H), 7.58-7.63 (m, 4H, Ar-H, azomethine-H), 7.71-7.73 (d, $J=8.40 \mathrm{~Hz}, 1 \mathrm{H}, \mathrm{Ar}-\mathrm{H})$, $7.87-7.91(\mathrm{~m}, 1 \mathrm{H}, \mathrm{Ar}-\mathrm{H}), 8.16-8.18(\mathrm{~d}, J=7.60 \mathrm{~Hz}, 1 \mathrm{H}$, Ar-H), 13.77 (s, 1H, NH). ${ }^{13} \mathrm{C}$ NMR (DMSO-d ${ }_{6}, \mathrm{ppm}$ ): $\delta 56.16\left(\mathrm{OCH}_{3}\right), 68.90\left(\mathrm{CH}_{2}\right), 114.29,114.40,116.40$, $116.63,121.49,123.39,124.50,126.92,127.06,127.89$, $128.14,131.53,131.62,132.44,135.39,147.09,149.65$ (2C), 151.64, 161.30, 161.79, 163.75, 169.87, 195.94 $(\mathrm{C}=\mathrm{S})$. Anal. calcd for $\mathrm{C}_{26} \mathrm{H}_{18} \mathrm{FN}_{3} \mathrm{O}_{4} \mathrm{~S}_{2}$ : C, 60.11; H, 3.49; N, 8.09. Found: C, 59.91; H, 3.59; N, 7.80.

5-\{4-[(3-(4-Chlorophenyl)-4-oxo-3,4-dihydroquinazolin-2-yl)methoxy]-3-methoxybenzylidene $\}$-2-thioxothiazolidin-4-one (43) Yield: 52\%, $\mathrm{mp} 239-241{ }^{\circ} \mathrm{C}$ (DMF/ $\left.\mathrm{H}_{2} \mathrm{O}\right) ;{ }^{1} \mathrm{H}$ NMR (DMSO-d $\left.\mathrm{d}_{6}, \mathrm{ppm}\right): \delta 3.82\left(\mathrm{~s}, 3 \mathrm{H}, \mathrm{OCH}_{3}\right)$, 4.84 (s, $\left.2 \mathrm{H}, \mathrm{CH}_{2}\right), 6.99-7.07(\mathrm{~m}, 2 \mathrm{H}, \mathrm{Ar}-\mathrm{H}), 7.16(\mathrm{~s}, 1 \mathrm{H}$, Ar-H), 7.55-7.63 (m, 6H, Ar-H, azomethine-H), 7.70$7.72(\mathrm{~d}, J=8.00 \mathrm{~Hz}, 1 \mathrm{H}, \mathrm{Ar}-\mathrm{H}), 7.87-7.90(\mathrm{t}, J=7.20 \mathrm{~Hz}$, $1 \mathrm{H}, \mathrm{Ar}-\mathrm{H}), 8.15-8.17$ (d, $J=8.00 \mathrm{~Hz}, 1 \mathrm{H}, \mathrm{Ar}-\mathrm{H}), 13.76$ (s, $1 \mathrm{H}, \mathrm{NH}) .{ }^{13} \mathrm{C}$ NMR (DMF-d, $\left.\mathrm{ppm}\right): \delta 56.19\left(\mathrm{OCH}_{3}\right)$, $69.56\left(\mathrm{CH}_{2}\right), 114.59,114.68,122.05,124.37,124.63$, 127.17, 127.79, 128.30 (2C), 130.01 (2C), 131.76 (2C), 132.30, 134.98, 135.47, 135.99, 147.71, 150.22, 150.40, 151.97, 162.15, 170.63, $196.76(\mathrm{C}=\mathrm{S})$. Anal. calcd for $\mathrm{C}_{26} \mathrm{H}_{18} \mathrm{ClN}_{3} \mathrm{O}_{4} \mathrm{~S}_{2}$ : C, 58.26; H, 3.38; N, 7.84. Found: C, 58.52; H, 3.34; N, 7.99.

5-\{4-[(3-(3-Chlorophenyl)-4-oxo-3,4-dihydroquinazolin-2-yl)methoxy]-3-methoxybenzylidene]-2-thioxothiazolidin-4-one (44) Yield: 52\%, mp 147-150 ${ }^{\circ} \mathrm{C}$ (DMF/ $\mathrm{EtOH}) ;{ }^{1} \mathrm{H}$ NMR (DMF-d $\left.{ }_{7}, \mathrm{ppm}\right): \delta 3.94\left(\mathrm{~s}, 3 \mathrm{H}, \mathrm{OCH}_{3}\right)$, $4.99\left(\mathrm{~s}, 2 \mathrm{H}, \mathrm{CH}_{2}\right), 7.09-7.10(\mathrm{~d}, J=8.50 \mathrm{~Hz}, 1 \mathrm{H}, \mathrm{Ar}-\mathrm{H})$, 7.14-7.16 (d, $J=8.00 \mathrm{~Hz}, 1 \mathrm{H}, \mathrm{Ar}-\mathrm{H}), 7.23(\mathrm{~s}, 1 \mathrm{H}, \mathrm{Ar}-\mathrm{H})$, 7.50-7.56 (m, 2H, Ar-H), 7.57 (s, $1 \mathrm{H}$, azomethine-H), 7.61-7.67 (m, 2H, Ar-H), 7.71-7.73 (d, $J=8.00,1 \mathrm{H}$, Ar-H), 7.82 (s, 1H, Ar-H), 7.89-7.92 (t, 1H, Ar-H), 8.18-8.20 (d, $J=7.00 \mathrm{~Hz}, 1 \mathrm{H}, \mathrm{Ar}-\mathrm{H}) .{ }^{13} \mathrm{C}$ NMR (DMF$\left.\mathrm{d}_{7}, \mathrm{ppm}\right): \delta 56.22\left(\mathrm{OCH}_{3}\right), 69.60\left(\mathrm{CH}_{2}\right), 114.43,114.45$, $122.03,124.19,124.58,127.15,127.71,128.30,128.36$, $128.61,129.96,130.25,131.27,132.38,134.42,135.48$, $138.40,147.62,150.11,150.30,151.76,162.09,170.39$, $196.60(\mathrm{C}=\mathrm{S})$. Anal. calcd for $\mathrm{C}_{26} \mathrm{H}_{18} \mathrm{ClN}_{3} \mathrm{O}_{4} \mathrm{~S}_{2}$ : C, 58.26; H, 3.38; N, 7.84. Found: C, 57.97; H, 3.47; N, 7.88.

5-\{4-[(3-(4-Bromophenyl)-4-oxo-3,4-dihydroquinazolin-2-yl)methoxy]-3-methoxybenzylidene\}-2-thioxothiazolidin-4-one (45) Yield: 51\%, $\mathrm{mp} 214-217^{\circ} \mathrm{C}\left(\mathrm{DMF} / \mathrm{H}_{2} \mathrm{O}\right)$ ${ }^{1} \mathrm{H}$ NMR (DMSO-d $\left.{ }_{6}, \mathrm{ppm}\right): \delta 3.80\left(\mathrm{~s}, 3 \mathrm{H}, \mathrm{OCH}_{3}\right), 4.85(\mathrm{~s}$, 2H, $\mathrm{CH}_{2}$ ), 6.98-7.16 (m, 2H, Ar-H), 7.46-7.72 (complex $\mathrm{m}, 8 \mathrm{H}, \mathrm{Ar}-\mathrm{H}$, azomethine-H), 7.85-7.91 (m, 1H, Ar-H), $8.14-8.17\left(\mathrm{dd}, J_{1}=1.20 \mathrm{~Hz}, J_{2}=8.10 \mathrm{~Hz}, 1 \mathrm{H}, \mathrm{Ar}-\mathrm{H}\right) .{ }^{13} \mathrm{C}$ NMR (DMSO-d $6, \mathrm{ppm}): \delta 55.66\left(\mathrm{OCH}_{3}\right), 68.43\left(\mathrm{CH}_{2}\right)$, 
$113.84,114.03,120.40,120.94,122.38,122.90,123.96$, $126.40,127.38,127.64,131.00$ (2C), 131.94, 132.12 (2C), $134.89,135.14,146.56,149.10,149.18,150.86,161.08$, 169.31, $195.41(\mathrm{C}=\mathrm{S})$. Anal. calcd for $\mathrm{C}_{26} \mathrm{H}_{18} \mathrm{BrN}_{3} \mathrm{O}_{4} \mathrm{~S}_{2}: \mathrm{C}$, 53.80; H, 3.13; N, 7.24. Found: C, 53.85; H, 2.79; N, 7.18.

5-\{4-[(3-(3-Bromophenyl)-4-oxo-3,4-dihydroquinazolin-2-yl)methoxy]-3-methoxybenzylidene,-2-thioxothiazolidin-4-one (46) Yield: 42\%, mp 243-245 ${ }^{\circ} \mathrm{C}$ (DMF/ $\mathrm{H}_{2} \mathrm{O}$ ); ${ }^{1} \mathrm{H}$ NMR (DMSO-d 6 , ppm): $\delta 3.85$ (s, 3H, $\mathrm{OCH}_{3}$ ), $4.83\left(\mathrm{~s}, 2 \mathrm{H}, \mathrm{CH}_{2}\right), 6.99-7.07(\mathrm{~m}, 2 \mathrm{H}, \mathrm{Ar}-\mathrm{H}), 7.16(\mathrm{~d}$, $J=1.60 \mathrm{~Hz}, 1 \mathrm{H}, \mathrm{Ar}-\mathrm{H}), 7.41-7.45(\mathrm{t}, J=8.00 \mathrm{~Hz}, 1 \mathrm{H}$, $\mathrm{Ar}-\mathrm{H}), 7.55-7.64(\mathrm{~m}, 4 \mathrm{H}, \mathrm{Ar}-\mathrm{H}$, azomethine $\mathrm{H}), 7.73-$ 7.75 (d, $J=8 \mathrm{~Hz}, 1 \mathrm{H}, \mathrm{Ar}-\mathrm{H}), 7.79$ (s, 1H, Ar-H), 7.88$7.92(\mathrm{t}, J=7.60 \mathrm{~Hz}, 1 \mathrm{H}, \mathrm{Ar}-\mathrm{H}), 8.15-8.17(\mathrm{~d}, J=8.00 \mathrm{~Hz}$, $1 \mathrm{H}, \mathrm{Ar}-\mathrm{H}), 13.76$ (s, 1H, NH). ${ }^{13} \mathrm{C}$ NMR (DMSO-d 6 , $\mathrm{ppm}): \delta$ 56.24 $\left(\mathrm{OCH}_{3}\right), 69.01\left(\mathrm{CH}_{2}\right), 114.15,114.17$, $121.50,121.94,123.36,124.49,126.94,127.06,127.94$, $128.27,128.55,131.34,132.41,132.49,132.59,135.47$, $137.74,147.03,149.50,149.58,151.23,161.63,169.83$, $195.92(\mathrm{C}=\mathrm{S})$. Anal. calcd for $\mathrm{C}_{26} \mathrm{H}_{18} \mathrm{BrN}_{3} \mathrm{O}_{4} \mathrm{~S}_{2}$ : C, 53.80; H, 3.13; N, 7.24. Found: C, 53.50; H, 2.96; N, 7.21.

5-\{4-[(3-(4-(Trifluoromethylphenyl)-4-oxo-3,4-dihydroquinazolin-2yl)methoxy]-3-methoxybenzylidene\}-2-thioxothiazolidin-4-one (47) Yield: 43\%, mp $165-168{ }^{\circ} \mathrm{C}$ (DMF/EtOH); ${ }^{1} \mathrm{H}$ NMR (DMSO-d $\left.6, \mathrm{ppm}\right): \delta 3.79$ (s, 3H, $\left.\mathrm{OCH}_{3}\right), 4.83\left(\mathrm{~s}, 2 \mathrm{H}, \mathrm{CH}_{2}\right), 6.98-7.05(\mathrm{~m}, 2 \mathrm{H}, \mathrm{Ar}-\mathrm{H})$, 7.13 (s, 1H, Ar-H), 7.56 (s, 1H, azomethine-H), 7.61$7.65(\mathrm{t}, J=7.60,1 \mathrm{H}, \mathrm{Ar}-\mathrm{H}), 7.69-7.79(\mathrm{~m}, 3 \mathrm{H}, \mathrm{Ar}-\mathrm{H})$, 7.86-7.93 (m, 2H, Ar-H), 7.96 (s, 1H, Ar-H), 8.16-8.18 $(\mathrm{d}, J=8.00 \mathrm{~Hz}, 1 \mathrm{H}, \mathrm{Ar}-\mathrm{H}), 13.76(\mathrm{~s}, 1 \mathrm{H}, \mathrm{NH}) .{ }^{13} \mathrm{C}$ NMR (DMSO-d $6, \mathrm{ppm}): \delta 56.00\left(\mathrm{OCH}_{3}\right), 69.09\left(\mathrm{CH}_{2}\right), 114.02$ (2C), 121.52, 122.76, 123.40, 124.40, 125.47, 126.53 (partially resolved $\mathrm{q}, J=4.0 \mathrm{~Hz}), 126.94,127.09,127.97$, $128.34,129.84$ (q, $J=32.0 \mathrm{~Hz}$ ), 130.83, 132.44, 133.71, 135.52, 137.13, 147.04, 149.32, 149.54, 151.19, 161.76, 169.82, $195.92(\mathrm{C}=\mathrm{S})$. Anal. calcd for $\mathrm{C}_{27} \mathrm{H}_{18} \mathrm{~F}_{3} \mathrm{~N}_{3} \mathrm{O}_{4} \mathrm{~S}_{2}: \mathrm{C}$, 56.94; H, 3.19; N, 7.38. Found: C, 56.63; H, 3.31; N, 7.49.

5-\{4-[(3-(4-Methylphenyl)-4-oxo-3,4-dihydroquinazolin-2-yl)methoxy]-3-methoxybenzylidene\}-2-thioxothiazolidin-4-one (48) Yield: 46\%, mp 172-175 ${ }^{\circ} \mathrm{C}$ (DMF/ $\mathrm{H}_{2} \mathrm{O}$ ); ${ }^{1} \mathrm{H}$ NMR (DMSO-d $\left.{ }_{6}, \mathrm{ppm}\right): \delta 2.32$ (s, 3H, $\left.\mathrm{CH}_{3}\right), 3.83\left(\mathrm{~s}, 3 \mathrm{H}, \mathrm{OCH}_{3}\right), 4.81\left(\mathrm{~s}, 2 \mathrm{H}, \mathrm{CH}_{2}\right), 6.95-6.97$ $(\mathrm{d}, J=8.40,1 \mathrm{H}, \mathrm{Ar}-\mathrm{H}), 7.04-7.06\left(\mathrm{dd}, J_{1}=1.60 \mathrm{~Hz}\right.$, $\left.J_{2}=8.40 \mathrm{~Hz}, 1 \mathrm{H}, \mathrm{Ar}-\mathrm{H}\right), 7.16-7.17(\mathrm{~d}, J=1.60 \mathrm{~Hz}, 1 \mathrm{H}$, Ar-H), 7.28-7.30 (d, $J=8.40 \mathrm{~Hz}, 2 \mathrm{H}, \mathrm{Ar}-\mathrm{H}), 7.38-7.40$ $(\mathrm{d}, J=8.40 \mathrm{~Hz}, 2 \mathrm{H}, \mathrm{Ar}-\mathrm{H}), 7.57-7.61(\mathrm{~m}, 2 \mathrm{H}, \mathrm{Ar}-\mathrm{H}$, azomethine-H), 7.68-7.70 (d, $J=8.00 \mathrm{~Hz}, 1 \mathrm{H}, \mathrm{Ar}-\mathrm{H})$, 7.84-7.89 (m, 1H, Ar-H), 8.14-8.16 (m, 1H, Ar-H), 13.76 (s, $1 \mathrm{H}, \mathrm{NH}) .{ }^{13} \mathrm{C}$ NMR (DMSO-d $6, \mathrm{ppm}$ ): $\delta 21.20$ $\left(\mathrm{CH}_{3}\right), 56.18\left(\mathrm{OCH}_{3}\right), 68.73\left(\mathrm{CH}_{2}\right), 114.40,114.49,121.53$,
$123.32,124.51,126.91,127.00,127.86,128.01,128.92$ (2C), 130.20 (2C), 132.47, 133.65, 135.27, 139.17, 147.16, 149.71, 149.82, 151.83, 161.72, 169.85, 195.93 (C=S). Anal. calcd for $\mathrm{C}_{27} \mathrm{H}_{21} \mathrm{~N}_{3} \mathrm{O}_{4} \mathrm{~S}_{2}$ : C, 62.90; H, 4.11; N, 8.15. Found: C, 62.96; H, 4.17; N, 7.98.

5-\{4-[(3-(3-Methylphenyl)-4-oxo-3,4-dihydroquinazolin-2-yl)methoxy]-3-methoxybenzylidene\}-2-thioxothiazolidin-4-one (49) Yield: 47\%, mp 154-156 ${ }^{\circ} \mathrm{C}$ (DMF/ $\mathrm{H}_{2} \mathrm{O}$ ); ${ }^{1} \mathrm{H}$ NMR (DMSO-d $\left.6, \mathrm{ppm}\right): \delta 2.27$ (s, 3H, $\mathrm{CH}_{3}$ ), $3.84\left(\mathrm{~s}, 3 \mathrm{H}, \mathrm{OCH}_{3}\right), 4.79\left(\mathrm{~s}, 2 \mathrm{H}, \mathrm{CH}_{2}\right), 6.94-6.96(\mathrm{~d}$, $J=8.40 \mathrm{~Hz}, 1 \mathrm{H}, \mathrm{Ar}-\mathrm{H}), 7.04-7.06(\mathrm{~d}, J=8.40 \mathrm{~Hz}, 1 \mathrm{H}$, Ar-H), 7.17-7.37 (m, 5H, Ar-H), 7.57-7.62 (m, 2H, Ar-H, azomethine-H), 7.71-7.73 (d, $J=8.00 \mathrm{~Hz}, 1 \mathrm{H}$, Ar-H), 7.87-7.90 (t, J = 7.60 Hz, $1 \mathrm{H}, \mathrm{Ar}-\mathrm{H}), 8.15-8.17$ $(\mathrm{d}, J=7.60 \mathrm{~Hz}, 1 \mathrm{H}, \mathrm{Ar}-\mathrm{H}), 13.76(\mathrm{~s}, 1 \mathrm{H}, \mathrm{NH}) .{ }^{13} \mathrm{C} \mathrm{NMR}$ (DMSO-d $\left.{ }_{6}, \mathrm{ppm}\right): \delta 21.18\left(\mathrm{CH}_{3}\right), 56.18\left(\mathrm{OCH}_{3}\right), 68.88$ $\left(\mathrm{CH}_{2}\right), 114.23(2 \mathrm{C}), 121.54,123.41,124.51,126.10$, $126.90,126.99,127.90,128.13,129.42,129.76,130.21$, $132.41,135.32,136.17,139.21,147.13,149.59,149.69$, $151.65,161.65,169.93,195.97(\mathrm{C}=\mathrm{S})$. Anal. calcd for $\mathrm{C}_{27} \mathrm{H}_{21} \mathrm{~N}_{3} \mathrm{O}_{4} \mathrm{~S}_{2}$ : C, 62.90; H, 4.11; N, 8.15. Found: C, 62.56; $\mathrm{H}, 4.20 ; \mathrm{N}, 7.85$.

5-\{4-[(3-(4-Methoxyphenyl)-4-oxo-3,4-dihydroquinazolin-2-yl)methoxy]-3-methoxybenzylidene\}-2-thioxothiazolidin-4-one (50) Yield: $48 \%, \mathrm{mp} 148-150{ }^{\circ} \mathrm{C}$ (DMF/ $\mathrm{H}_{2} \mathrm{O}$ ); ${ }^{1} \mathrm{H}$ NMR (DMSO-d 6 , ppm): $\delta 3.80\left(\mathrm{~s}, 3 \mathrm{H}, \mathrm{OCH}_{3}\right.$ ), $3.83\left(\mathrm{~s}, 3 \mathrm{H}, \mathrm{OCH}_{3}\right), 4.81\left(\mathrm{~s}, 2 \mathrm{H}, \mathrm{CH}_{2}\right), 6.95-7.07(\mathrm{~m}, 4 \mathrm{H}$, Ar-H), 7.16 (s, 1H, Ar-H), 7.40-7.42 (d, $J=8.70,2 \mathrm{H}$, Ar-H), 7.57-7.61 (m, 2H, Ar-H, azomethine-H), 7.677.70 (m, 1H, Ar-H), 7.84-7.89 (m, 1H, Ar-H), 8.14-8.16 (d, $J=8.10 \mathrm{~Hz}, 1 \mathrm{H}, \mathrm{Ar}-\mathrm{H}) .{ }^{13} \mathrm{C}$ NMR (DMSO-d $\left.6, \mathrm{ppm}\right)$ : S $55.85\left(\mathrm{OCH}_{3}\right), 56.20\left(\mathrm{OCH}_{3}\right), 68.77\left(\mathrm{CH}_{2}\right), 114.39$, $114.47,114.85$ (2C), 121.54, 123.31, 124.54, 126.92, $126.98,127.84,127.98,128.68,130.33$ (2C), 132.49, $135.25,147.16,149.70,149.87,152.12,159.93,161.88$, 169.86, $195.94(\mathrm{C}=\mathrm{S})$. Anal. calcd for $\mathrm{C}_{27} \mathrm{H}_{21} \mathrm{~N}_{3} \mathrm{O}_{5} \mathrm{~S}_{2}: \mathrm{C}$, 61.00; H, 3.98; N, 7.90. Found: C, 61.10; H, 3.90; N, 8.07.

\section{Biology \\ Cell culture and assessment of cytotoxicity}

The compounds were tested for their cytotoxic activity on a solid tumor cell line, i.e. HT-1080 originating from a fibrosarcoma (American Type Culture Collection; ATCC, Rockville, MD, USA), and on two leukemia cell lines, i.e. the HL-60 human promyelocytic leukemia (European Collection of Animal Cell Cultures; ECACC, Salisbury, UK) and the K-562 human chronic myelogenous leukemia (ATCC). Furthermore, the human skin fibroblast strain AG01523 (Coriell Institute for Medical Research, Camden, NJ, USA) was also used as normal control. 
Adherent cells were routinely cultured in Dulbecco's minimal essential medium (DMEM), and leukemia cells in RPMI 1640, in an environment of $5 \% \mathrm{CO}_{2}, 85 \%$ humidity, and $37{ }^{\circ} \mathrm{C}$. All media were supplemented with penicillin $(100 \mathrm{U} / \mathrm{ml})$, streptomycin $(100 \mu \mathrm{g} / \mathrm{ml})$ (media and antibiotics from Biochrom KG, Berlin, Germany), and $10 \%$ fetal bovine serum (Life Technologies Europe BV, Thessaloniki, Greece). Adherent cells were subcultured using a trypsin $(0.25 \%$; Life Technologies Europe BV)citrate (0.30\%; Sigma, St. Louis, MO, USA) solution. The cytotoxicity assay was performed by a modification of the MTT method [41, 42]. Briefly, the cells were plated in flat-bottomed 96-well microplates at a density of 5000 cells/well, and incubated overnight before the addition of serial dilutions of the test compounds. The cells were incubated with the compounds or the corresponding vehicle (DMSO) concentrations for 3 days. Then, the medium was replaced with MTT (Sigma) in serum-free, phenol-red-free DMEM $(1 \mathrm{mg} / \mathrm{ml})$. After incubation for $4 \mathrm{~h}$, the MTT formazan was solubilized in 2-propanol, and the optical density was measured using a FLUOstar Optima (BMG Labtech, Ortenberg, Germany) microplate reader at a wavelength of $550 \mathrm{~nm}$ (reference wavelength $660 \mathrm{~nm}$ ). Doxorubicin hydrochloride (Sigma) was included in the experiments as positive control. The results represent the mean of three independent experiments and are expressed as $\mathrm{IC}_{50}[42]$.

\section{Western analysis of protein expression}

Apoptosis was estimated based on caspase-3 cleavage, as previously described [40]. Briefly, exponentially growing HL-60 cells were incubated with the test molecules at $50 \mu \mathrm{M}$ for $48 \mathrm{~h}$. Cell lysates were collected in hot sample buffer $(62.5 \mathrm{mM}$ Tris, $\mathrm{pH} 6.8,6 \% \mathrm{w} / \mathrm{v}$ SDS, $2 \%$ v/v glycerol, $5 \% \mathrm{v} / \mathrm{v} 2$-mercaptoethanol, $0.0125 \% \mathrm{w} / \mathrm{v}$ bromophenol blue, and protease and phosphatase inhibitor cocktails), sonicated for $15 \mathrm{~s}$, clarified by centrifugation and stored at $-800{ }^{\circ} \mathrm{C}$ until use. They were separated on $12.5 \%$ SDS-PAGE and the proteins were transferred to Polyscreen PVDF membranes (Perkin Elmer, Thessaloniki, Greece). After blocking with $5 \%(w / v)$ non-fat dried milk in $10 \mathrm{mM}$ Tris-HCl, $\mathrm{pH}$ 7.4, $150 \mathrm{mM} \mathrm{NaCl}$, and $0.05 \%$ Tween-20 (TTBS) buffer, membranes were incubated with the appropriate primary antibodies, i.e. rabbit polyclonal anti-caspase-3 (Cell Signaling Technology, Hertfordshire, UK) or mouse monoclonal antiactin (Neomarkers, Lab Vision Corporation, Fremont, CA, USA). Then, they were washed with TTBS, incubated with either anti-mouse or anti-rabbit horseradish peroxidase-conjugated goat secondary antibody (Sigma), washed again with TTBS and the immunoreactive bands were visualized by chemiluminescence (LumiSensor HRP Substrate Kit, GenScript, Piscataway, NJ, USA) according to the manufacturer's instructions on a Fujifilm LAS4000 luminescent image analyzer (Fujifilm Manufacturing, Greenwood, SC, USA).

\section{Intracellular reactive oxygen species determination}

Intracellular ROS accumulation was studied using a modification of the DCFH-DA method [43]. In particular, HT-1080 cells were plated in black flat-bottomed 96-well microplates at a density of 10,000 cells/well, and left to adhere overnight. Then, they were loaded with $10 \mu \mathrm{M} 2^{\prime}, 7^{\prime}$-dichlorofluorescein diacetate (DCFH-DA) for $1 \mathrm{~h}$, followed by addition of the test molecules at $10 \mu \mathrm{M}$. Fluorescence at $520 \mathrm{~nm}$ after excitation at $480 \mathrm{~nm}$ was measured at various time-points using a FLUOstar Optima microplate reader. The last measurement was taken at $48 \mathrm{~h}$ post stimulation. Then, the cells were fixed in $20 \%$ methanol, stained with $0.5 \% \mathrm{w} / \mathrm{v}$ crystal violet in $20 \%$ methanol, and the wells were washed with deionized water. The stain was solubilized in $10 \%$ acetic acid, and the absorbance was measured in the above microplate reader at $550 \mathrm{~nm}$. DCF fluorescence was normalized to the cell number, as assessed indirectly by the crystal violet staining.

\section{Conclusions}

Among the rhodanines reported in the present study, compounds 45, 43, 47 and 37 were the most active, especially against leukemia cell lines, exhibiting in vitro cytotoxic activity in the low micromolar range. Structure-activity relationship of the tested compounds revealed that bulky, hydrophobic, and electron-withdrawing substituents at the para-position of the quinazolinone 3-phenyl ring enhance cytotoxicity. In addition, methoxy substitution on the central benzene ring was also found to have a positive impact on cytotoxicity. Selectivity against cancer cells as opposed to normal ones was also observed. Mechanistic studies revealed that the most cytotoxic target compounds exhibit pro-apoptotic activity and trigger oxidative stress in cancer cells. In our ongoing research project, further in depth mechanistic investigation as well as molecular modeling studies will be performed to obtain novel therapeutic candidates with improved pharmacological profile.

\footnotetext{
Authors' contributions

KM proposed the research work and designed the chemical experiments. SE carried out synthesis, purification and characterization experiments. HP and DK performed the biological assays. KM, SE, DK and HP collaborated in the writing of manuscript. AE, LA and KM supervised the whole work. All authors read and approved the final manuscript.

\section{Author details}

${ }^{1}$ Department of Medicinal Chemistry, Faculty of Pharmacy, Zagazig University, Zagazig, Egypt. ${ }^{2}$ Laboratory of Cell Proliferation and Ageing, Institute of Biosciences and Applications, National Centre of Scientific Research "Demokritos", Athens, Greece.
} 


\section{Acknowledgements}

The authors would like to thank the Faculty of Pharmacy, Zagazig University, for partial financial support of this work.

\section{Competing interests}

The authors declare that they have no competing interests.

\section{Sample availability}

Samples of the compounds are available from the authors.

\section{Publisher's Note}

Springer Nature remains neutral with regard to jurisdictional claims in published maps and institutional affiliations.

Received: 21 July 2017 Accepted: 5 October 2017

Published online: 13 October 2017

\section{References}

1. Mendgen T, Steuer C, Klein C (2012) Privileged scaffolds or promiscuous binders: a comparative study on rhodanines and related heterocycles in medicinal chemistry. J Med Chem 55:743-753

2. Ramirez M, Borja N (2008) Epalrestat: an aldose reductase inhibitor for the treatment of diabetic neuropathy. Pharmacotherapy 28:646-655

3. Hotta N, Kawamori R, Fukuda M, Shigeta Y (2012) Long-term clinical effects of epalrestat, an aldose reductase inhibitor, on progression of diabetic neuropathy and other microvascular complications: multivariate epidemiological analysis based on patient background factors and severity of diabetic neuropathy. Diabet Med 29:1529-1533

4. Hotta N, Akanuma Y, Kawamori R, Matsuoka K, Oka Y, Shichiri M, Toyota T, Nakashima M, Yoshimura I, Sakamoto N, Shigeta Y (2006) Longterm clinical effects of epalrestat, an aldose reductase inhibitor, on diabetic peripheral neuropathy: the 3-year, multicenter, comparative aldose reductase inhibitor-diabetes complications trial. Diabetes Care 29:1538-1544

5. Goto Y, Hotta N, Shigeta Y, Sakamoto N, Kikkawa R (1995) Effects of an aldose reductase inhibitor, epalrestat, on diabetic neuropathy. Clinical benefit and indication for the drug assessed from the results of a placebo-controlled double-blind study. Biomed Pharmacother 49:269-277

6. Ikeda T, Iwata K, Tanaka Y (1999) Long-term effect of epalrestat on cardiac autonomic neuropathy in subjects with non-insulin dependent diabetes mellitus. Diabetes Res Clin Pract 43:193-198

7. Hotta N, Sakamoto N, Shigeta Y, Kikkawa R, Goto Y (1996) Clinical investigation of epalrestat, an aldose reductase inhibitor, on diabetic neuropathy in Japan: multicenter study. Diabetic Neuropathy Study Group in Japan. J Diabetes Complic 10:168-172

8. Wang L, Kong F, Kokoski C, Andrews D, Xing C (2008) Development of dimeric modulators for anti-apoptotic Bcl-2 proteins. Bioorg Med Chem Lett 18:236-240

9. Xing C, Wang L, Tang X, Sham Y (2007) Development of selective inhibitors for anti-apoptotic BCl-2 proteins from BHI-1. Bioorg Med Chem 15:2167-2176

10. Li H, Yang J, Ma S, Qiao C (2012) Structure-based design of rhodaninebased acylsulfonamide derivatives as antagonists of the anti-apoptotic Bcl-2 protein. Bioorg Med Chem 20:4194-4200

11. Bernardo P, Sivaraman T, Wan K, Xu J, Krishnamoorthy J, Song C, Tian L, Chin J, Lim D, Mok H, Yu V, Tong J, Chai C (2010) Structural insights into the design of small molecule inhibitors that selectively antagonize Mcl-1. J Med Chem 53:2314-2318

12. Degterev A, Lugovskoy A, Cardone M, Mulley B, Wagner G, Mitchison T, Yuan J (2001) Identification of small-molecule inhibitors of interaction between the $\mathrm{BH} 3$ domain and $\mathrm{BCl}-\mathrm{xL}$. Nat Cell Biol 3:173-182

13. Chandrappa S, Kavitha C, Shahabuddin M, Vinaya K, Kumar C, Ranganatha S, Raghavan S, Rangappa K (2009) Synthesis of 2-(5-((5-(4-chlorophenyl) furan-2-yl)methylene)-4-oxo-2-thioxothiaz-olidin-3-yl)acetic acid derivatives and evaluation of their cytotoxicity and induction of apoptosis in human leukemia cells. Bioorg Med Chem 17:2576-2584
14. Moorthy B, Ravi S, Srivastava M, Chiruvella K, Hemlal H, Joy O, Raghavan S (2010) Novel rhodanine derivatives induce growth inhibition followed by apoptosis. Bioorg Med Chem Lett 20:6297-6301

15. Ravi S, Chiruvella K, Rajesh K, Prabhu V, Raghavan S (2010) 5-Isopropylidene-3-ethyl rhodanine induce growth inhibition followed by apoptosis in leukemia cells. Eur J Med Chem 45:2748-2752

16. Wang H, Hammoudeh D, Follis A, Reese B, Lazo J, Metallo S, Prochownik E (2007) Improved low molecular weight Myc-Max inhibitors. Mol Cancer Ther 6:2399-2408

17. Ahn J, Kim S, Park W, Cho S, Ha J, Kim S, Kang S, Jeong D, Jung S, Lee S, Kim H, Park S, Lee K, Lee C, Ryu S, Choi J (2006) Synthesis and biological evaluation of rhodanine derivatives as PRL-3 inhibitors. Bioorg Med Chem Lett 16:2996-2999

18. Min G, Lee S, Kim H, Han Y, Lee R, Jeong D, Han D, Kwon B (2013) Rhodanine-based PRL-3 inhibitors blocked the migration and invasion of metastatic cancer cells. Bioorg Med Chem Lett 23:3769-3774

19. Kawakami M, Koya K, Ukai T, Tatsuta N, Ikegawa A, Ogawa K, Shishido T, Chen L (1998) Structure-activity of novel rhodacyanine dyes as antitumor agents. J Med Chem 41:130-142

20. Fahmy H, Bekhit A (2002) Synthesis of some new bis-thiazoles as possible anticancer agents. Pharmazie 57:800-803

21. Azizmohammadi M, Khoobi M, Ramazani A, Emami S, Zarrin A, Firuzi O, Miri R, Shafiee A (2013) 2H-chromene derivatives bearing thiazolidine2,4-dione, rhodanine or hydantoin moieties as potential anticancer agents. Eur J Med Chem 59:15-22

22. Ramesh V, Rao B, Sharma P, Swarna B, Thummuri D, Srinivas K, Naidu V, Rao V (2014) Synthesis and biological evaluation of new rhodanine analogues bearing 2-chloroquinoline and benzo[h]quinoline scaffolds as anticancer agents. Eur J Med Chem 83:569-580

23. Kawakami M, Koya K, Ukai T, Tatsuta N, Ikegawa A, Ogawa K, Shishido T, Chen L (1997) Synthesis and evaluation of novel rhodacyanine dyes that exhibit antitumor activity. J Med Chem 40:3151-3160

24. Havrylyuk D, Mosula L, Zimenkovsky B, Vasylenko O, Gzella A, Lesyk R (2010) Synthesis and anticancer activity evaluation of 4-thiazolidinones containing benzothiazole moiety. Eur J Med Chem 45:5012-5021

25. Chen H, Fan Y, Natarajan A, Guo Y, lyasere J, Harbinski F, Luus L, Christ W, Aktas H, Halperin J (2004) Synthesis and biological evaluation of thiazolidine-2,4-dione and 2,4-thione derivatives as inhibitors of translation initiation. Bioorg Med Chem Lett 14:5401-5405

26. Russell A, Westwood I, Crawford M, Robinson J, Kawamura A, Redfield C, Laurieri N, Lowe E, Davies S, Sim E (2009) Selective small molecule inhibitors of the potential breast cancer marker, human arylamine $\mathrm{N}$-acetyltransferase 1, and its murine homologue, mouse arylamine $\mathrm{N}$-acetyltransferase 2. Bioorg Med Chem 17:905-918

27. Muhammad S, Ravi S, Thangamani A (2016) Synthesis and evaluation of some novel $\mathrm{N}$-substituted rhodanines for their anticancer activity. Med Chem Res 25:994-1004

28. Dago C, Ambeu C, Coulibaly W, Békro Y, Mamyrbékova J, Defontaine A, Baratte B, Bach S, Ruchaud S, Guével R, Ravache M, Corlu A, Bazureau J (2015) Synthetic development of new 3-(4-arylmethylamino) butyl-5-arylidene-rhodanines under microwave irradiation and their effects on tumor cell lines and against protein kinases. Molecules 20:12412-12435

29. Senkiv J, Finiuk N, Kaminsky D, Havrylyuk D, Wojtyra M, Kril I, Gzella A, Stoik R, Lesyk R (2016) 5-Ene-4-thiazolidinones induce apoptosis in mammalian leukemia cells. Eur J Med Chem 117:33-46

30. Szychowski K, Leja M, Kaminskyy D, Binduga U, Pinyazhko O, Lesyk R, Gmiński J (2017) Study of novel anticancer 4-thiazolidinone derivatives. Chem Biol Interact 262:46-56

31. Kamal A, Bharathi E, Ramaiah M, Dastagiri D, Reddy J, Viswanath A, Sultana F, Pushoavalli S, Bahdra M, Srivastava H, Sastry G, Juvekar A, Sen S, Zingde S (2010) Quinazolinone linked pyrrolo[2,1-c][1, 4]benzodiazepine (PBD) conjugates: design, synthesis and biological evaluation as potential anticancer agents. Bioorg Med Chem 18:526-542

32. Mahdavi M, Pedrood K, Safavi M, Saeedi M, Pordeli M, Ardestani S, Emami S, Adib M, Foroumadi A, Shafiee A (2015) Synthesis and anticancer activity of $\mathrm{N}$-substituted 2-arylquinazolinones bearing trans-stilbene scaffold. Eur J Med Chem 95:492-499

33. Palem J, Alugubelli G, Bantu R, Nagarapu L, Polepalli S, Jain S, Bathini R, Manga V (2016) Quinazolinones-phenylquinoxaline hybrids with 
unsaturation/saturation linkers as novel anti-proliferative agents. Bioorg Med Chem Lett 26:3014-3018

34. Venkatesh R, Ramaiah M, Gaikwad H, Janardhan S, Bantu R, Nagarapu L, Sastry G, Ganesh A, Bahdra M (2015) Luotonin-A based quinazolinones cause apoptosis and senescence via HDAC inhibition and activation of tumor suppressor proteins in HeLa cells. Eur J Med Chem 94:87-101

35. Zhang G, Xue W, An Y, Yuan J, Qin J, Pan C, Su G (2015) Distinct nove quinzolinone exhibits selective inhibition in MGC-803 cancer cells by dictating mutant p53 function. Eur J Med Chem 95:377-387

36. Domanig R (1981) Synthese und einige reaktionen von 2-azidomethyl3-aryl-4-chinazolinonen. Monatshefte fur Chemie 112:1195-1202

37. Fetter J, Czuppon T, Hornyak G, Feller A (1991) The synthesis of some 3-amino-2-halomethyl-,2-halomethyl-3-(subst.amino)- and 2-halomethyl3-hetarylquinazolin-4(3H)-ones as potential plant protecting agents. Tetrahedron 47:9393-9410

38. Tani J, Yamada Y, Oine T, Ochiai T, Ishida R, Inoue I (1979) Studies on biologically active halogenated compounds. 1. Synthesis and central nervous system depressant activity of 2-(fluoromethyl)-3-aryl-4(3H)quinazolinone derivatives. J Med Chem 22:95-99
39. Giri R, Thaker H, Giordano T, Williams J, Rogers D, Vasu K, Sudarsanam $V$ (2010) Design, synthesis and evaluation of novel 2-thiophen-5-yl$3 \mathrm{H}$-quinazolin-4-one analogues as inhibitors of transcription factors NF-KB and AP-1 mediated transcriptional activation: their possible utilization as anti-inflammatory and anti-cancer agents. Bioorg Med Chem 18:2796-2808

40. Metwally K, Pratsinis H, Kletsas D (2017) Novel 2,4-thiazolidinediones: synthesis, in vitro cytotoxic activity, and mechanistic investigation. Eur J Med Chem 133:340-350

41. Denizot F, Lang R (1986) Rapid colorimetric assay for cell growth and survival: modifications to the tetrazolium dye procedure giving improved sensitivity and reliability. J Immunol Methods 89:271-277

42. Pratsinis H, Kletsas D, Melliou E, Chinou I (2010) Antiproliferative activity of Greek propolis. J Med Food 13:286-290

43. Anastasiadi M, Pratsinis H, Kletsas D, Skaltsounis A, Haroutounian S (2010) Bioactive non-coloured polyphenols content of grapes, wines and vinification by-products: evaluation of the antioxidant activities of their extracts. Food Res Int 43:805-813

\section{Submit your manuscript to a SpringerOpen ${ }^{\circ}$ journal and benefit from:}

- Convenient online submission

- Rigorous peer review

- Open access: articles freely available online

- High visibility within the field

- Retaining the copyright to your article

Submit your next manuscript at $\boldsymbol{\nabla}$ springeropen.com 